\title{
Impacto de remisiones tributarias en las micro, pequeñas y medianas empresas año 2018, Cuenca - Ecuador.@() () ()
}

Impact of tax remissions in micro, small and medium enterprises, year 2018, Cuenca- Ecuador.

Oscar Calle Masache. ${ }^{1}$, Edison Becerra Molina. ${ }^{2}$, Tito Banegas Peña. ${ }^{3}$ \& Geovanny Zamora Zamora. ${ }^{4}$

Recibido: 10-04-2019 / Revisado: 25-04-2019 /Aceptado: 05-05-2019/ Publicado: 16-06-2019

\section{Abstract. $\quad$ DOI: https://doi.org/10.33262/cienciadigital.v3i2.3.593}

In the Republic of Ecuador, with the purpose of improving the economic situation of the country in relation to liquidity, generation of employment and promotion of national and foreign investment, the "Organic Law for Productive Development, Investment Attraction, Generation of Employment, and Stability and Fiscal Equilibrium ". The first two sections deal with the remission of interest, fines and surcharges of tax, fiscal and customs duties; those corresponding to vehicle taxes, registration and traffic infractions, employer obligations in default, glosses and credit titles of the Ecuadorian Social Security Institute, basic services of Public Enterprises and the tax and non-tax obligations of the Decentralized Autonomous Governments, In the first instance, an analysis of the aforementioned legal body was carried out, which basically implies a bibliographical investigation; In addition, a field investigation was conducted with the students of the Business Administration course, obtaining first-hand information through a survey of a sample of 385 microentrepreneurs from the city of Cuenca; Most of them are unaware of the effects of the law and have not incurred in

${ }^{1}$ Universidad Católica de Cuenca, Cuenca, Ecuador, ocalle@ucacue.edu.ec

2 Universidad Católica de Cuenca, Cuenca, Ecuador, jbecerram@ucacue.edu.ec

${ }^{3}$ Universidad Católica de Cuenca, Cuenca, Ecuador, tbanegasp@ucacue.edu.ec

${ }^{4}$ Universidad Católica de Cuenca, Cuenca, Ecuador, ezamoraz@ucacue.edu.ec 
tax infractions, so they have not experienced any benefits. The application of the Law, it can be affirmed that it is a tool that encourages tax evasion, because it generates the cancellation of interest and fines to individuals and legal entities that have incurred in tax, fiscal, customs and employer violations, and not to responsible entrepreneurs who have fulfilled their responsibilities to the state.

Keywords: Tributes, mipymes, taxpayers, incentives

\section{Resumen.}

En la república del Ecuador, con el propósito de mejorar la situación económica del país en relación a la liquidez, generación de empleo y fomento de la inversión nacional y extranjera, se creó la "Ley Orgánica para el Fomento Productivo, Atracción de Inversiones, Generación de Empleo, y Estabilidad y Equilibrio Fiscal”. En las dos primeras secciones se trata sobre la remisión de intereses, multas y recargos de obligaciones tributarias, fiscales y aduaneras; las que corresponden a impuestos vehiculares, matriculación e infracciones de tránsito, obligaciones patronales en mora, glosas y títulos de crédito del Instituto ecuatoriano de Seguridad Social, servicios básicos de las Empresas Públicas y las obligaciones tributarias y no tributarias de los Gobiernos Autónomos Descentralizados, En primera instancia, se realizó un análisis del referido cuerpo legal, lo que implica básicamente una investigación bibliográfica; adicionalmente se realizó una investigación de campo con los estudiantes de la carrera de Administración de Empresas, obteniendo información de primera mano por medio de una encuesta a una muestra de 385 microempresarios de la ciudad de Cuenca; La mayoría de ellos, desconocen los efectos de la ley y no han incurrido en infracciones tributarias por lo que no han experimentado ningún beneficio. La aplicación de la Ley, se puede afirmar que se trata de una herramienta que incentiva la evasión tributaria, porque genera la condonación de intereses y multas a las personas naturales y jurídicas que han incurrido en infracción de orden tributaria, fiscal, aduanera y patronal, y no así a los emprendedores responsables que han cumplido con sus responsabilidades para con el estado. 
Palabras claves: Tributos, mipymes, contribuyentes, incentivos.

\section{Introducción.}

El momento histórico en el que se encuentra el Ecuador, como consecuencia del cambio de gobierno y de la implementación de una serie de medidas económicas aplicadas por éste, a partir de mayo de 2017, ha generado la pérdida progresiva de liquidez. Cabe destacar entre algunas de estas medidas, como se puede advertir a continuación: eliminación de las sobre tasas arancelarias, incremento del porcentaje del impuesto a la renta, exoneración del impuesto a la renta por el tiempo de 5 a 10 años, el reconocimiento de la obligación del estado para el pago del $40 \%$ de las jubilaciones a favor del Instituto Ecuatoriano de Seguridad Social, el incremento del precio de la gasolina súper y del diésel para las industrias, entre las más sobresalientes.

Esta situación económica ha motivado para la implementación de la "Ley Orgánica para el fomento productivo, atracción de inversiones, generación de empleo, y estabilidad y equilibrio fiscal", en la que se generan varios beneficios a favor de los empresarios. Una de las medidas más polémicas, está la condonación de intereses y multas para los contribuyentes que no han cumplido con sus obligaciones tributarias, aduaneras, de tránsito y con la seguridad social.

Por lo expuesto, se pretende determinar el porcentaje de los micro, pequeños y medianos empresarios de la ciudad de Cuenca que se han beneficiado o se van a acoger a la aplicación de esta Ley, así como también estudiar la percepción de los empresarios que han cumplido oportunamente con sus obligaciones para con el estado.

En el presente trabajo se expondrá el análisis de campo realizado sobre el tema, el criterio de microempresarios sobre los beneficios que han tenido o van a tener a futuro; $y$, finalmente se sustentarán conclusiones en base a las investigaciones realizadas.

\section{Metodologia.}

En la elaboración del Proyecto está ligado con el diseño de campo y el nivel descriptivo, en cuanto se analizaron la aplicación de las remisiones de intereses, multas y recargos de obligaciones de deudas tributarias o fiscales internas, las obligaciones aduaneras, 
obligaciones patronales en mora, becas o créditos educativos, matriculación vehicular, servicios básicos vencidos, procedimientos de ejecución de coactiva, responsabilidad civil culposa a trabajadores de la salud y deudas adquiridas por compra venta de cartera en la ciudad de Cuenca, cuya población sujeto de estudio corresponde a 385 Mipymes, por medio de la técnica de la encuesta a través de la herramienta SPSS; permitió obtener de los sujetos de investigación la información necesaria para el análisis pertinente.

La Unidad Académica de Administración de la UCACUE, con su carrera de Administración de Empresas coadyuvan para la aplicación de los instrumentos de recolección de información, mismos que una vez analizados se articulan a la Ley de Fomento Productivo, mediante el proceso de condonación de intereses, multas y recargos, medida esta que permitió que el Gobierno Ecuatoriano obtenga liquidez a corto y mediano plazo.

\section{Fundamentación Teórica}

El presente trabajo de investigación se fundamenta en la condonación de intereses y multas para los contribuyentes que no han cumplido con sus obligaciones tributarias, aduaneras, de tránsito y con la seguridad social, servicios básicos de las Empresas Públicas y las obligaciones tributarias y no tributarias de los Gobiernos Autónomos Descentralizadas, los resultados evidencian que las MIPYMES, en las que se encuentran las empresas del sector primario (industriales), empresa del sector secundario (comerciales), y empresas del sector terciario (De servicios), han mantenido obligaciones pendientes con el Servicio de Rentas Internas.

El análisis indico la importancia de las Mipymes que se basa en el desarrollo social del País produciendo demanda, y comprando productos o añadiendo un valor agregado, en la producción de bienes y servicios, instaurándose de esta manera un eslabón concluyente en el encadenamiento de la actividad económica y la generación de empleo.

Las personas jurídicas como las Sociedades y Compañías que realizan actividades económicas lícitas amparadas en una figura legal propia, están obligadas a inscribirse en el Registro Único de Contribuyentes (RUC); emitir y entregar comprobantes de venta 
autorizados por el SRI por todas sus transacciones y presentar declaraciones de impuestos de acuerdo a su actividad económica.

Por su parte, las mismas deberán llevar la contabilidad bajo la responsabilidad y con la firma de un contador público legalmente autorizado e inscrito en el Registro Único de Contribuyentes (RUC), por el sistema de partida doble, en idioma castellano y en dólares de los Estados Unidos.

Como es lógico, Las obligaciones tributarias que estas organizaciones deben pagar son:

Declaración del Impuesto al Valor Agregado (IVA)

Declaración del Impuesto a la Renta (IR)

Declaración de retenciones en la fuente del Impuesto a la renta

Pago del Anticipo a la Renta (AR)

Pago del Impuesto a la Salida de Divisas (ISD)

Presentación del anexo de retenciones en la fuente por relación de dependencia (RDEP)

Presentación del anexo transaccional simplificado (ATS)

Presentación del anexo de impuesto a los consumos especiales (AICE)

Presentación de anexo de accionistas, participes, socios, miembros de directorio y administradores (APS)

Anexo de dividendos (ADI)

Declaración patrimonial-DPT/ anexo de activos y pasivos de sociedades y establecimientos permanentes.

La información recogida permitió determinar el incumplimiento de las normas vigentes establecidas como la condonación de impuestos, mismas que fueron sancionadas de conformidad a lo establecido en el Código Tributario, que causaron una mayor carga tributaria que pudiesen haber afectado de hecho a la parte financiera de las empresas.

\section{Resultados.}

Para abordar los temas sobre el impacto de remisiones tributarias en las micro, pequeñas y medianas empresas en año 2018 de la ciudad de Cuenca, república del Ecuador; es necesario revisar los siguientes conceptos: 
Es conveniente destacar que los tributos son ingresos de derecho público que consisten en prestaciones pecuniarias obligatorias, impuestas unilateralmente por el Estado, exigidas por una administración pública como consecuencia de la realización del hecho imponible al que la ley vincule en el deber de contribuir al desarrollo del país, Servicio de rentas internas SRI (2019).

Los tributos en términos generales tienen los siguientes propósitos: a) redistribución de la riqueza de un estado y b) cambios en las conductas del consumo de los habitantes.

Incentivo: Para la economía, un incentivo es un estímulo que se ofrece a una persona, una empresa o un sector con el objetivo de incrementar la producción y mejorar el rendimiento, COSEDE (2018).

Los incentivos deberían cumplir con el propósito de facilitar el pago de los impuestos, de generar un cumplimiento más responsable de las obligaciones tributarias, de mejorar el desempeño empresarial de los contribuyentes y de fortalecer la cultura tributaria de los ciudadanos.

Por otra parte, el impuesto a la renta es el que grava la utilidad de las personas, empresas, u otras entidades legales.

En el Ecuador se mantiene el principio de progresividad en el pago del impuesto a la renta, propendiendo a que las personas naturales o jurídicas que más utilidades generen en el año, sean las que más paguen; este elemento es utilizado para regular las finanzas públicas.

El Impuesto al Valor Agregado (IVA)- es un tributo indirecto que grava a las ventas y demás transferencias de bienes movibles (mercaderías, productos) y a la prestación de algunos servicios, Servicio de rentas internas - SRI (2019).

Este impuesto asume el nombre de "Valor Agregado" porque grava a todas las etapas de comercialización, dando lugar al hecho generador en cada una de ellas.

Cuando este impuesto es alterado por los diferentes gobiernos de turno, la afectación es de forma general a todos los habitantes que realizan adquisiciones. 
Es importante señalar que la reactivación, llamada también en ocasiones recuperación, es la fase del ciclo económico que se caracteriza por la reanimación de las actividades económicas, aumenta el empleo, la producción, la inversión y las ventas; constituyéndose en los objetivos de los diferentes gobiernos y que dependiendo de las políticas fiscales que adopten pueden o no alcanzarlos.

El Ecuador, luego de haber afrontado con éxito los choques económicos internos y externos durante los años 2015 y 2016, en el año 2017 experimentó un crecimiento de 2,4\% sobre el PIB, para el año 2018 el crecimiento fue del 1\% y 2019 se proyecta que la economía del Ecuador crecerá el 0,7\% de acuerdo al Fondo Monetario Internacional; lo que significa que el país se encuentra en un proceso recesivo que dará como resultado el deterioro de los principales indicadores económicos.

En torno a la remisión tributaria podemos indicar que es un modo de extinción de las obligaciones tributarias establecido por Ley, a través de la cual el legislador, de manera unilateral, condona o perdona a los contribuyentes y responsables, con ánimo de liberalidad, el cumplimiento del todo o parte de sus obligaciones, Servicio de rentas internas - SRI (2019).

Esta estrategia ha sido utilizada por varias ocasiones en el Ecuador, con propósitos, impactos y resultados diferentes, como son: mejorar la liquidez del estado, beneficiar de forma importante a las empresas y grupos económicos más poderosos del sistema y finalmente se estimula la práctica de la evasión tributaria.

Por su parte la obligación tributaria es un término que procede del latín "obligatio" y que refiere a algo que una persona está forzada a hacer por una imposición legal o por una exigencia moral. La obligación crea un vínculo que lleva al sujeto a hacer o a abstenerse de hacer algo de acuerdo a las leyes o las normativas.

En el país se ha avanzado en forma importante en mejorar la cultura tributaria, pero aún persisten sectores de contribuyentes que se resisten a cumplir con sus obligaciones tributarias con el estado. 
Respecto a las opiniones emitidas la condonación es el acto y el resultado de condonar, eximir o perdonar el pago de una deuda o el cumplimiento de una condena. En este caso, podemos exponer que se trata de una palabra que deriva del latín, exactamente procede del verbo "condonare", que puede traducirse como "perdonar una deuda o condena", Balas (2018).

La aplicación de la "Ley Orgánica para el Fomento Productivo, Atracción de Inversiones, Generación de Empleo, y Estabilidad y Equilibrio Fiscal”, en lo más relevante se trataba de favorecer a personas y grupos económicos que mantenían deudas importantes con el estado que sumadas representa una cantidad aproximada a los 4.200 millones de dólares de los Estados Unidos de Norte América, MIPRO. (2018)

Otro aspecto que hemos tomado en cuenta es lo referente a la las MIPYMES, que es el acrónimo de micro, pequeña y mediana empresa. Se trata de la empresas comerciales, mercantiles, industriales o de otro tipo que tiene un número reducido de trabajadores y que registra ingresos moderados controladas Revista Ekos Negocios (2018).

Así mismo según la Revista Ekos Negocios (2018). Potestad es un concepto que deriva del término en latín "potestas". En el plano legal potestad está asociado al poder que tiene alguien sobre algo para plasmar su poder sobre alguien o algo. Se entiende por potestad como un derecho de aquel que la dispone.

En lo que respecta a la multa es la sanción administrativa o penal consistente en un pago en dinero a veces expresado como días de multa (cuando su pago redime la reclusión por el número correspondiente de días).

Por su parte el interés en economía y finanzas, es un índice utilizado para medir la rentabilidad de los ahorros e inversiones así también el costo de un crédito.

De igual forma los impuestos son tributos exigidos por el Estado a los contribuyentes o negocios con fines de lucro, cuyo hecho imponible se constituye por actos jurídicos o económicos que deben ser pagados en función del patrimonio, de acuerdo a rentas percibidas y a la adquisición de bienes o servicios personales Paz y Miño, (2015). Se clasifican en: 
directos, indirectos, reales, personales, internos, externos, ordinarios, proporcionales y progresivos.

Futuro, C. T. (2018). Afirma que "Se considera como impuesto aquella prestación exigida por el Estado en virtud de su potestad de imperio, y que el contribuyente se ve obligado a pagar por encontrarse en el caso previsto por la disposición legal que consulta la existencia del tributo." (p.21)

Otro aspecto que se consideró en nuestra investigación son las tasas, que son pagos que realizan los sujetos pasivos, por los servicios públicos prestados directamente a estos por parte del Estado. Se clasifican en: tasas de carácter municipal y tasas de carácter nacional Paz y Miño, (2015).

Contribuciones especiales y de mejoras. Son tributos que tienen que ser pagados por aquellos sujetos pasivos que se benefician de las obras realizadas por el Estado, ya que favorecen el patrimonio de estos contribuyentes.

Para dar sustento al estudio realizado sobre la aplicación de la "Ley Orgánica para el fomento productivo, atracción de inversiones, generación de empleo, y estabilidad y equilibrio fiscal", se realizó el siguiente análisis teórico:

Según el capítulo I, Régimen de remisiones reducciones; Sección Primera, Remisión de intereses, multas y recargos de obligaciones tributarias, fiscales y aduaneras, en el Artículo 1. Remisión de interés, multas y recargos, se legisla lo siguiente:

Se dispone la remisión del 100\% de intereses, multas y recargos derivados del saldo de las obligaciones tributarias o fiscales internas cuya administración y/o recaudación le corresponde únicamente al Servicio de Rentas Internas conforme los términos y condiciones establecidos en la presente Ley y las resoluciones que para el efecto emita el Servicio de Rentas Internas.

Las obligaciones tributarias o fiscales vencidas con posterioridad al 2 de abril de 2018, así como las obligaciones correspondientes a la declaración anual del impuesto a la renta del ejercicio fiscal 2017, no podrán acogerse a la remisión prevista en este artículo. 
En lo relativo a la remisión de las cuotas del Régimen Impositivo Simplificado RISE, así como lo relacionado a la remisión y saneamiento de los valores que componen la matriculación vehicular, se deberá aplicar lo establecido en los artículos 9 y 11 de la presente Ley.

Todas las referencias a "contribuyentes" realizadas en el presente Capítulo, deberán entenderse de forma general a "sujetos pasivos" de conformidad con los términos contenidos en el Código Tributario.

En los artículos siguientes se establecen aspectos relacionados a los plazos, a pagos previos y parciales, a las declaraciones de obligaciones durante el período de remisión, sobre las facilidades de pago del capital, aspectos sobre procesos administrativos y judiciales pendientes, se establecen normas para los contribuyentes pertenecientes al régimen impositivo simplificado (RISE).

El análisis indicó que actualmente, existen USD 4600 millones que no han podido ser recaudados debido a juicios tributarios. De esa cifra, el 50\% corresponde a capital y el resto a intereses, la amnistía ha beneficiado a un $10 \%$ de las pequeñas y medianas empresas de forma directa, de la Cámara de la Pequeña y Mediana de Comercio de Pichincha (Capeipi), gremio que está integrado por cerca de 1200 empresas.

Se determinó que los sectores de este segmento con mayor nivel de endeudamiento con la Seguridad Social y el SRI son el maderero, textil y de la construcción.

Orlando L. (2018) declara que, "por el número de contribuyentes, en el año 2015, el sector más beneficiado con la primera etapa de la Ley de Remisión (condonación del 100\% de intereses, multas y recargos) fue el comercial. Con una participación del 30,9\% de más de 1 millón de contribuyentes, esta primera fase, el Servicio de Rentas Internas (SRI) recaudó un total de USD 932 millones. El monto superó en USD 332 millones la meta inicial, que fue de USD 600 millones". Esta medida fue asumida para contrarrestar los efectos de situaciones económicas externas tales como las devaluaciones monetarias adoptadas por los gobiernos de Colombia y Perú, Disminución del precio del petróleo y la revalorización de dólar de los Estados Unidos de Norte América, entre otras. 
Es importante destacar, que la última remisión tributaria, en 2015, el fisco obtuvo \$970 millones pagados por un millón de contribuyentes, según datos del SRI. Marisol Andrade, directora general de la entidad, explicó que el 92\% de contribuyentes de aquel proceso fueron personas naturales y apenas el $8 \%$ sociedades. Lo que contrasta con las proyecciones del proceso que se encuentra en ejecución.

De acuerdo a la opinión de varios expertos, se pronostica que la cultura tributaria en el Ecuador se deteriorará, pues, la medida incentiva la evasión, como es el criterio de Larry Yumibanda, presidente del Colegio de Economistas del Guayas, que manifiesta que "El Gobierno no debería indultar las deudas porque perjudica a la cultura de pagar impuestos. La evasión tributaria en Ecuador bordea el 4\% del Producto Interno Bruto (PIB), señaló y sugirió poner un candado constitucional para evitar futuras condonaciones".

A criterio de Katiuska King (2018), La búsqueda de incentivos se basa en la premisa falsa de que sin ellos no habrá inversión productiva, lo cual no es nuevo en el país, lo grave es que se olvida de los estímulos ya recibidos y se normaliza como práctica de ciertos gremios empresariales que se victimizan. Solo la reducción de tres puntos al impuesto a la renta generado en el Código de la Producción implicó un sacrificio tributario de alrededor de 300 millones de dólares. Esta nueva ley no incluye estimaciones del sacrificio fiscal ni de las inversiones previstas ni del empleo que se espera generar. Lo que implica que se está creando en la conciencia colectiva que el estado debe seguir protegiendo y generando incentivos para el sector empresarial en detrimento del bienestar de los grupos vulnerables de la sociedad.

Analistas más radicales como es el caso de Jonathan Báez (2019), sostiene que;

La "Ley Orgánica para el fomento productivo", atracción de inversiones, generación de empleo, y estabilidad y equilibrio fiscal", denominada Ley Trole 3, es una auto-emboscada que situará como única salida dos procesos:

i) El contraer deuda con organismos multilaterales, como por ejemplo el FMI. Mismo que situó sus garras nuevamente en América Latina con uno de los mayores salvatajes observados, el préstamo de USD 50 mil millones en Argentina y; 
2) La disminución del gasto social. Dicho proceso se dará a través de dos pilares fundamentales:

a) Disminución de los ingresos fiscales vía remisión de deudas, exoneración de impuestos progresivos (renta y divisas), aliento a la evasión y elusión fiscal a través de paraísos fiscales, así como el cambio de la forma de contratos petroleros; $y$,

b) Prohibición del déficit primario para la aprobación del presupuesto general del Estado, en otras palabras, disminuir las inversiones en salud, educación, despidos y/o disminución de salarios.

Respecto a los ingresos fiscales, es sumamente simbólico que el primer artículo de dicha Ley trate sobre la remisión de deudas por concepto de impuestos.

Las élites del Ecuador y América Latina- se caracterizan por su accionar en tres dimensiones fundamentales:

i) Pugnar por la disminución del tamaño del Estado;

ii) No permitir avances en temas laborales y;

iii) Impedir a toda costa el pago de impuestos, sobre todo progresivos- (Paz y Miño, 2015; 2016). En ese contexto, es importante mencionar que 166 grupos económicos tienen una deuda con el Servicio de Rentas Internas que asciende a más de USD 2.260 millones. Los 10 mayores deudores concentran el 79\% del total (con corte al 28 de agosto de 2017). Es decir, el $6 \%$ de deudores es responsable del $79 \%$ de las deudas, mismas que solventarían las necesidades de financiamiento estatal.

Por lo tanto, la remisión beneficiaría a un limitado número de élites al servicio del capital local y transnacional, lo que implicaría un desfalco para las arcas del Estado.

En otras palabras, la Ley Trole 3 es claramente un articulado al servicio de las élites. De igual forma, la eliminación del anticipo al impuesto a la renta deja una puerta libre para que la elusión tenga lugar. 
Visto con esta perspectiva, el panorama económico del Ecuador a futuro se presenta con muchas dificultades que generará el deterioro del nivel de vida de las grandes mayorías.

Es importante señalar que la información recogida permitió determinar que el estado condonó intereses, multas y recargos de deudas tributarias de personas y empresas. En todos los casos, las remisiones tuvieron efecto, una vez que el contribuyente pagó la totalidad del capital de acuerdo a plazos determinados, en temas tributarios referente a las siguientes instituciones: Servicio de Rentas Internas- SRI, Instituto Ecuatoriano de Seguridad Social - IESS, Agencia Nacional de Transito- ANT, Aduanas del Ecuador- SENAE, Empresas Publicas, Gobiernos Autónomos Descentralizados-GAD, Instituto de Crédito Educativo (IECE), Superintendencia de Compañías, Banca cerrada, Contraloría, Autoridad Única de Agua y Banco Nacional de Fomento.

Los resultados evidencian que las obligaciones tributarias que se beneficiaron con el $100 \%$ de la remisión son: Cuotas de RISE. Matriculación vehicular, deudas en proceso de cobro, inclusive las suspendidas por impugnaciones administrativas o judiciales.

El análisis indico que el grupo de beneficiarios, estuvo conformado de dos grupos. En el grupo uno para pagar la totalidad del capital el SRI dio un plazo de 90 días hábiles, dentro de los contribuyentes contemplados en el grupo uno están las empresas, cuyo promedio de ingreso bruto de los últimos 3 años sea mayor a USD 5 millones, Integrantes de Grupos Económicos, las empresas que están operando a la fecha de entrada en vigencia de la ley, los sujetos pasivos que mantengan impuestos retenidos, percibidos y pendientes de pago al 2 de abril del 2018. Para el caso del grupo dos para solicitar facilidades de pago o para pagar la totalidad de capital, todos los contribuyentes no contemplados en el grupo unos pudieron solicitar facilidades de pago hasta dos años, cuotas mensuales iguales sin cuota inicial, dos años a partir de la fecha de la publicación de la Ley. No aplica en impuestos retenidos o percibidos, ASAMBLEA NACIONAL. (2017). 
En cuanto a las excepciones legales no se acogieron obligaciones pendientes de impuestos a la renta del ejercicio fiscal 2017, además de las obligaciones vencidas después del 2 de abril de 2018.

Por su parte las deudas impugnadas para acogerse a la remisión el contribuyente deberá pagar el capital adeudado y desistir de las impugnaciones administrativas y judiciales, en relación a las acciones el contribuyente no podrá iniciar acciones legales posteriores sobre las deudas canceladas bajo remisión, la remisión aplicó con el pago total del capital dentro de los plazos.

Los metas de la remisión tributaria determinadas por el Servicio de Rentas Internas por el año 2018, es de \$ 602 millones, total gestionado \$ 1.268 millones, \$ 1.101 millones por recaudación efectiva, \$ 167 millones facilidades de pago y 350 mil contribuyentes beneficiarios que pertenece al 95,50\%, que corresponde a micro, pequeños y medianos contribuyentes.

En relación, a las encuestas realizadas a 385 a micro, pequeños y medianos contribuyentes. (MIPYMES), entre las que se incluyen también las Instituciones gubernamentales y empresas públicas, según su actividad o giro, obteniendo los siguientes resultados.

El análisis indico que de las 385 encuestas realizadas en la ciudad de Cuenca de las cuales 69 empresas que representa el 17,92\% corresponden al sector primario industriales, 194 con el 50,39\%, pertenecen a las empresas del sector secundario - Comerciales y por ultimo 122 empresas con el 31,69\% son del sector terciario - Servicios, por tanto, las empresas que más se han beneficiado a la remisión tributaria son las empresas comerciales.

Tabla. 1. MIPYMES según su actividad o giro

\begin{tabular}{lrrr}
\hline \multicolumn{1}{c}{ MIPYMES según su actividad o giro } & Frecuencia & \multicolumn{1}{c}{$\%$} & \% Acumulado \\
\hline Empresas del sector primario: Industriales & 69 & $17,92 \%$ & $17,92 \%$ \\
Empresas del sector secundario: & & & \\
Comerciales & 194 & $50,39 \%$ & $68,31 \%$ \\
Empresas del sector terciario: De Servicios & 122 & $31,69 \%$ & $100,00 \%$ \\
$\quad$ TOTAL: & 385 & $100,00 \%$ & \\
\hline
\end{tabular}

Fuente: Encuesta de remisiones y reducciones

Elaborado por: Autores 
Gráfico.1. MIPYMES según su actividad

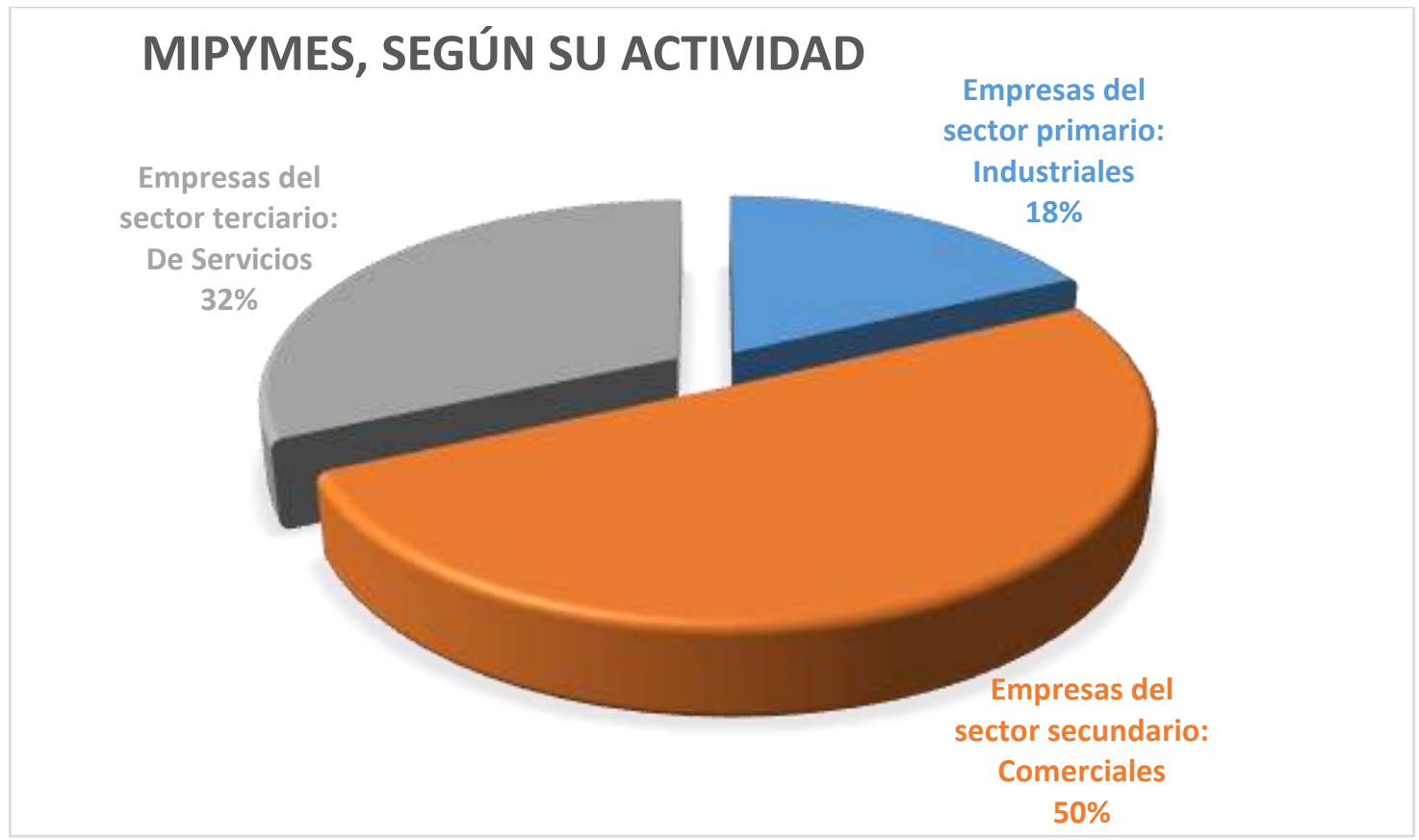

Fuente: Encuesta de remisiones y reducciones

Cabe destacar también los resultados de las MIPYMES, según su tamaño de los 385 instrumentos de recolección realizadas a 138 Microempresas posen menos de diez trabajadores. que representa el 35,84\%, 132 corresponden a pequeña empresa que tienen entre 11 y 49 trabajadores, con un porcentaje del 34,29\%, 95 encuestados pertenecen a la mediana empresa, poseen entre 50 y 250 trabajadores, con el 24,68\%, y por ultimo 20 encuestados corresponden a la Gran Empresa, cuyas empresas tienen más de 250 trabajadores, con el 5,19\%, de este modo, es evidente que las empresas que han sido encuestadas son en un buen numero las microempresas, le sigue muy de cerca la pequeña empresa. 
Tabla. 2. MIPYMES, según su tamaño.

\begin{tabular}{|c|c|c|c|}
\hline MIPYMES, según su tamaño & Frecuencia & $\%$ & $\begin{array}{c}\% \\
\text { Acumulado } \\
\end{array}$ \\
\hline Micro empresa: si posee 10 o menos trabajadores. & 138 & $35,84 \%$ & $35,84 \%$ \\
\hline $\begin{array}{l}\text { Pequeña empresa: si tiene un número entre } 11 \text { y } 49 \\
\text { trabajadores. }\end{array}$ & 132 & $34,29 \%$ & $70,13 \%$ \\
\hline $\begin{array}{l}\text { Mediana empresa: si tiene un número entre } 50 \text { y } 250 \\
\text { trabajadores. }\end{array}$ & 95 & $24,68 \%$ & $94,81 \%$ \\
\hline Gran empresa: si posee más de 250 trabajadores. & 20 & $5,19 \%$ & $100,00 \%$ \\
\hline TOTAL: & 385 & $100,00 \%$ & \\
\hline
\end{tabular}

Fuente: Encuesta de remisiones y reducciones

Elaborado por: Autores

Gráfico.2. MIPYMES según su tamaño

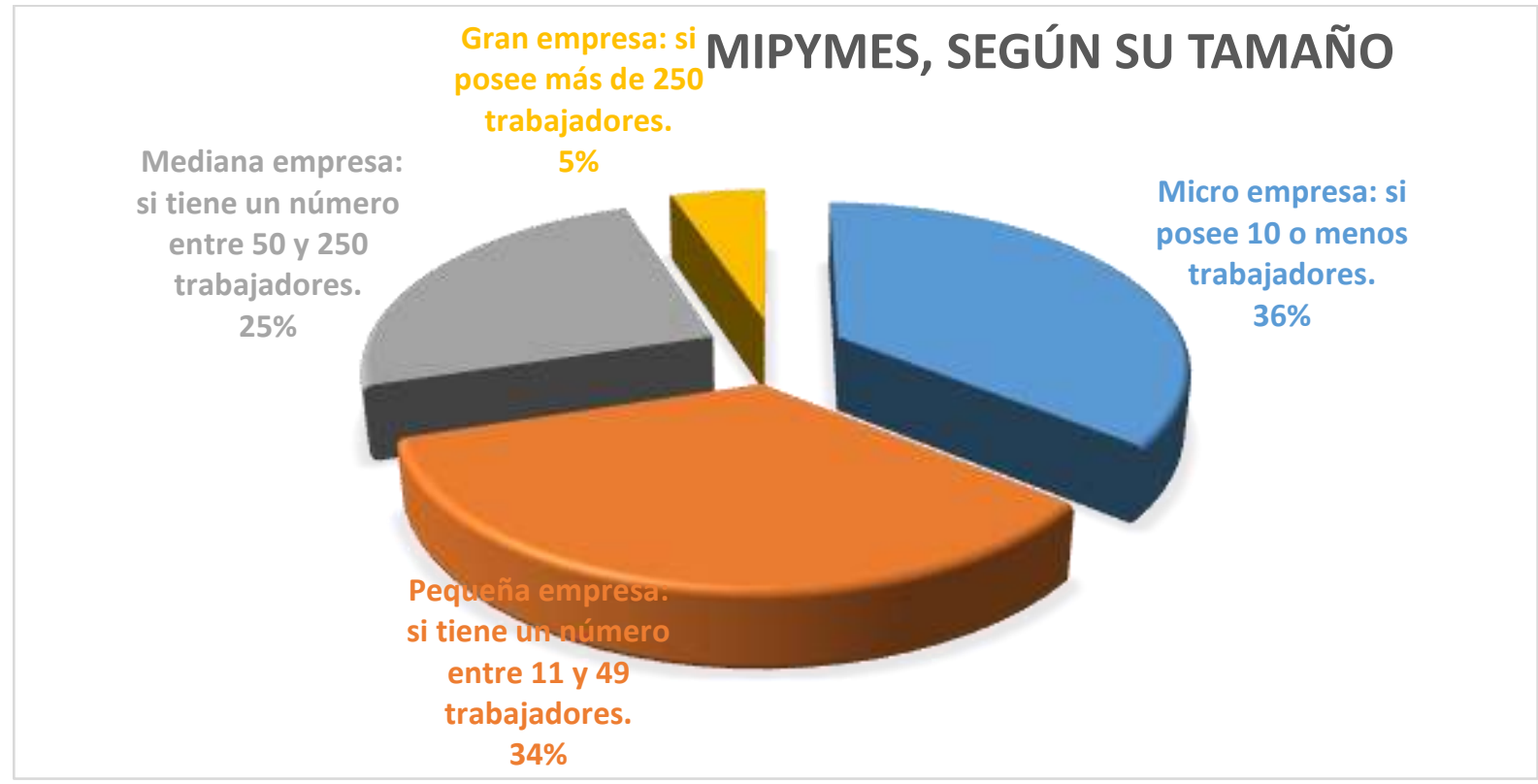

Fuente: Encuesta de remisiones y reducciones

Por su parte, según las 385 encuestas realizadas con respecto a la clasificación de Mipymes que se han acogido a las remisiones y reducciones referentes a retrasos de obligaciones tributarias al Servicio de Rentas Internas - SRI en un numero 132 que representan el 34,29\%, así mismo 52 Mipymes, que representan el 13,51\%, se han acogido a las remisiones del Instituto Ecuatoriano de Seguridad Social- IESS, 8 remisiones de empresas a la Agencia Nacional de tránsito- ANT, con el 2,08\%, 6 empresas que han accedido a las remisiones 
básicamente de Etapa y la Electrica Centro Sur, que representan el 1,56\%, 3 Mipymes que han accedido a las remisiones otorgadas por el Gobierno Autónomo Descentralizado- GAD cuenca por pago de mejoras, con el 0,78\%, 2 Mipymes que han accedido a la remisión de las Aduana del Ecuador-SENAE, por obligaciones aduaneras, y existen 182 empresas de las encuestadas que se encuentran con sus obligaciones al día y no fue necesario acceder a remisiones y reducciones alguna, representando un 47,27\%.

Tabla. 3. Clasificación de MIPYMES que se han acogido a las remisiones y reducciones.

\begin{tabular}{lrrr}
\hline $\begin{array}{l}\text { Clasificación de MIPYMES que se han acogido a las } \\
\text { remisiones y reducciones }\end{array}$ & Frecuencia & \multicolumn{1}{c}{$\%$} & \% Acumulado \\
\hline Servicio de Rentas Internas -SRI & 132 & $34,29 \%$ & $34,29 \%$ \\
Instituto Ecuatoriano de Seguridad Social- IESS. & 52 & $13,51 \%$ & $47,79 \%$ \\
Agencia Nacional de tránsito- ANT. & 8 & $2,08 \%$ & $49,87 \%$ \\
Empresas Públicas & 6 & $1,56 \%$ & $51,43 \%$ \\
Gobierno Autónomo Descentralizado- GAD. & 3 & $0,78 \%$ & $52,21 \%$ \\
Aduana del Ecuador-SENAE. & 2 & $0,52 \%$ & $52,73 \%$ \\
Mipymes no sujetas a remisiones e intereses & 182 & $47,27 \%$ & $100,00 \%$ \\
$\quad$ TOTAL: & 385 & $52,73 \%$ & \\
\hline
\end{tabular}

Fuente: Encuesta de remisiones y reducciones Elaborado por: Autores

Gráfico.3. MIPYMES según su tamaño

\section{CLASIFICACIÓN E MIPYMES QUE SE HAN ACOGIDO A LAS REMISIONES}

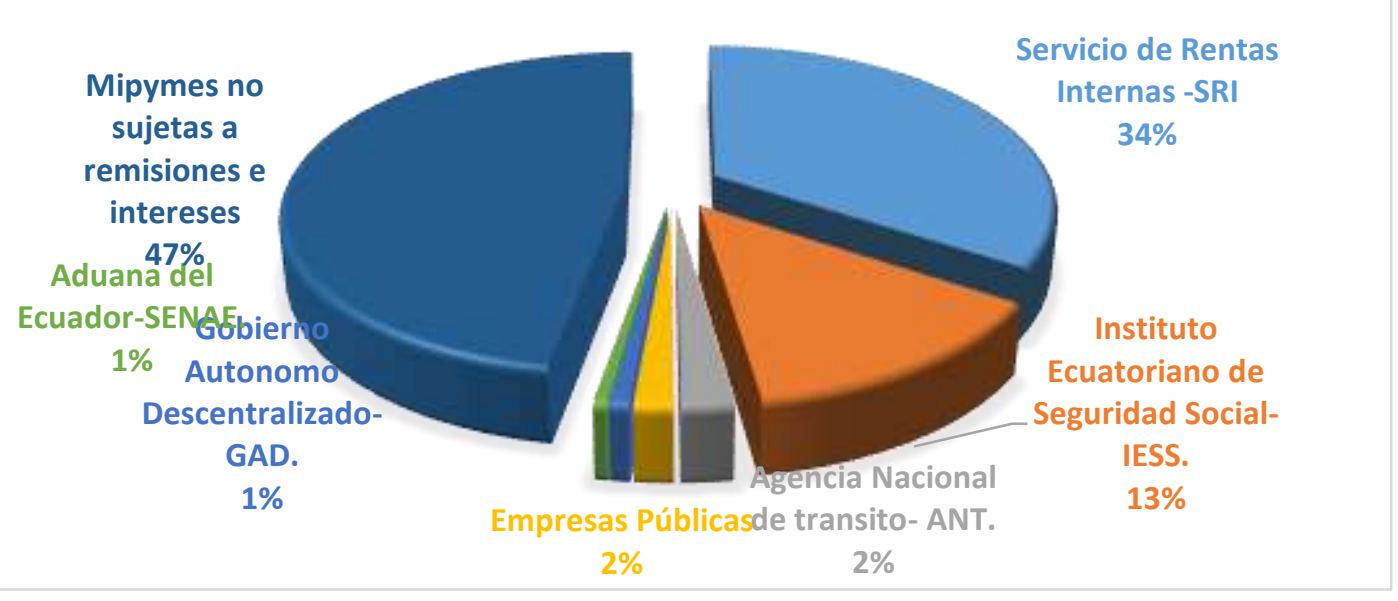

Fuente: Encuesta de remisiones y reducciones 


\section{Conclusiones.}

- Las remisiones de las obligaciones tributarias que los contribuyentes mantienen con el estado, se puede considerar como una estrategia o política pública que tiene como objetivo mejorar la situación económica que atraviesa el país y las condiciones de vida de toda la población, generando estímulos que motiven a que los contribuyentes cumplan de forma responsable con sus obligaciones.

- La aplicación de la "Ley Orgánica para el Fomento Productivo, Atracción de Inversiones, Generación de Empleo, y Estabilidad y Equilibrio Fiscal”, está generando resultados positivos en el objetivo de recaudar los impuestos que se encontraban vencidos a costa de perdonar cuatro mil doscientos millones de dólares de los Estados Unidos de Norte América, que representa una cantidad superior a la que se proyecta recaudar hasta el año 2020.

- El análisis indico que las Mipymes que lo constituyen personas naturales y jurídicas de la ciudad de cuenta es el sector comercial que porcentualmente representa el $50,39 \%$ y que son los sectores más beneficiados que han mantenido importantes deudas vencidas con el Servicio de Rentas Internas.

- Es conveniente destacar que, de la investigación realizada, las Mipymes con respecto a su tamaño, son las microempresas que disponen menos de diez trabajadores las que en un porcentaje del 35,84\% han sido las beneficiarias con el proceso de condonación de intereses, multas y recargos de conformidad a la ley de fomento productivo.

- Los datos contenidos en la tabla $\mathrm{N}^{\circ} 3$, nos ofrece valiosa información sobre las remisiones y reducciones; así como también nos proporciona importante información científica de las 385 encuestas realizadas con respecto a la clasificación de Mipymes que se han acogido a las remisiones y reducciones referentes a retrasos de obligaciones tributarias al Servicio de Rentas Internas -SRI en un porcentaje del $34,29 \%$, en las que están inmersos tanto personas naturales como jurídicas, por deudas tributarias o fiscales internas, en tanto que las Mipymes, que representan el $13,51 \%$, se han acogido a las remisiones del Instituto Ecuatoriano de Seguridad Social- IESS, por obligaciones patronales en mora, en glosa, títulos de crédito por responsabilidad patronal, en relación a las remisiones de empresas a la Agencia 
Nacional de tránsito- ANT, con el 2,08\%, por matriculación vehicular, infracciones de tránsito, impuestos vehiculares, en lo que respecta a las empresas públicas han accedido a las remisiones básicamente por servicios básicos de la empresa Etapa de Cuenca y la Empresa Eléctrica Centro Sur, que representan el 1,56\%, por otra parte las Mipymes que han accedido a las remisiones otorgadas por el Gobierno Autónomo Descentralizado- GAD, por obligaciones tributarias, no tributarias y de servicios básicos vencidas, con el 0,78\%, del mismo modo las Mipymes que han accedido a la remisión de las Aduana del Ecuador-SENAE, por obligaciones aduaneras establecidas en control posterior a través de rectificaciones de tributos, tal como lo señale la investigación realizada existen personas y organizaciones que cumplen de forma responsable con sus obligaciones tributarias y no accedieron a remisiones y reducciones, y que representa el $47,27 \%$.

\section{Referencias bibliográficas.}

Asamblea Nacional. (2010). Ley Orgánica de Educación Superior. Quito: Asamblea Nacional. CES. Gaceta oficial No 298 del 12 de octubre del 2010.

Balás, J. (2018). Reactivación Económica Ecuatoriana: ¿Impacta al sector productivo en el primer semestre del año 2018? INNOVA Research Journal, 165-166.

COSEDE. (25 de 01 de 2018). Cosede. Obtenido de Cosede.gob.ec: https://www.cosede.gob.ec/wp-content/uploads/downloads/2018/01/LEYORGANICA-PARA-LA-REACTIVACION-DE-LA-ECONOMIAFORTALECIMIENTO-DE-LA-DOLARIZACION-Y-MODERNIZACION-DELA-GESTION-FINANCIERA.pdf

EKOS. (31 de 12 de 2018). ekosnegocios.com. recuperado de: www.ekosnegocios.com: http://www.ekosnegocios.com/negocios/verArticuloContenido.aspx ?idArt=11190

Futuro, C. t. (01 de 12 de 2018). Cuida tu futuro. Recuperado de: Cuida tu futuro: https://cuidatufuturo.com/pasos-crear-empresa-ecuador/

MIPRO. (2018). Ministerio de Industrias y productividad. Quito: Ecuador. Gaceta oficial No 253 de fecha agosto del 2012

Paz y Miño, J. (2015). Deuda Histórica e Historia Inmediata en América Latina, Colombia: Bogotá Ediciones CCC - Centro Cultural de la Cooperación. 
SERVICIO DE RENTAS INTERNAS. (11 de 01 de 2019). Ley Orgánica para la Reactivación de la Economía, Fortalecimiento de la Dolarización y Modernización de la Gestión Financiera. Obtenido de Servicio de Rentas Internas: Recuperado de: http://www.sri.gob.ec/web/guest/ley-organica-para-la-reactivacion-de-la-economia$\mathrm{y}$-fortalecimiento

\section{PARA CITAR EL ARTÍCULO INDEXADO.}

alle Masache, O., Becerra Molina, E., Banegas Peña, T., \& Zamora Zamora, G. (2019). Impacto de remisiones tributarias en las micro, pequeñas y medianas empresas año 2018 , Cuenca - Ecuador. Ciencia Digital, 3(2.3), 136-155. https://doi.org/10.33262/cienciadigital.v3i2.3.593

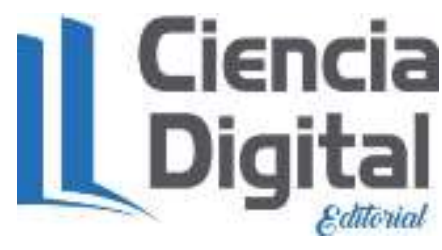

El artículo que se publica es de exclusiva responsabilidad de los autores y no necesariamente reflejan el pensamiento de la Revista Ciencia Digital.

El artículo queda en propiedad de la revista y, por tanto, su publicación parcial y/o total en otro medio tiene que ser autorizado por el director de la Revista Ciencia Digital.
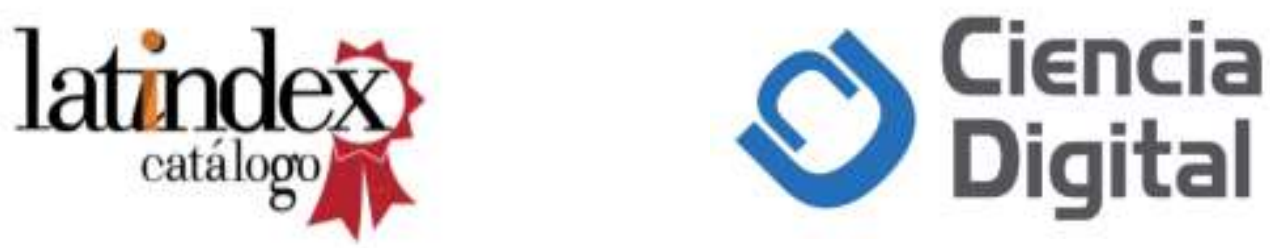